Available online at GSC Online Press Directory

GSC Biological and Pharmaceutical Sciences

e-ISSN: 2581-3250, CODEN (USA): GBPSC2

\title{
Typhoid infection and its effect on liver function assessment among pregnant women in Owerri, Imo State, Nigeria
}

\author{
Ike Christian Chukwuemeka ${ }^{1,}{ }^{*}$, Akwari Dike Kalu ${ }^{1}$, Ogwuegbu Happiness Odinakachi ${ }^{2}$ and Chikezie John \\ Austin ${ }^{3}$ \\ ${ }^{1}$ Department of Biological Sciences (Microbiology Programme), College of Basic and Applied Sciences, Rhema University \\ Nigeria, P.M.B. 7021 Aba, Abia State, Nigeria. \\ 2 Department of Microbiology, Abia State University Uturu, P.M.B. 2000 Uturu, Abia State, Nigeria. \\ ${ }^{3}$ Department of Internal Medicine, Abia State University Uturu. P.M.B. 2000 Uturu, Abia State, Nigeria.
}

Publication history: Received on 29 May 2019; revised on 21 July 2019; accepted on 25 July 2019

Article DOI: https://doi.org/10.30574/gscbps.2019.8.1.0096

\begin{abstract}
Typhoid infection and its effect on liver function assessment among pregnant women were evaluated. Serum and blood samples were collected and processed for liver function assessment, widal test and microbiological identification of Salmonella typhi using standard methods. A total of ninety (90) patients were studied. Serum alanine transaminase (ALT) and Serum aspartate transaminase (AST) values for healthy pregnant women and pregnant women with typhoid infection had progressive value increase with increase in pregnancy time, except for the slight reduction in the third trimester with ALT. Mean values of healthy pregnant women and pregnant women with typhoid infection (iu/L) for ALT and AST were (8.93 $\pm 1.07 / 9.95 \pm 0.19 ; 7.52 \pm 0.45 / 8.50 \pm 0.14)$ at first trimester, (10.62 $\pm 1.19 / 11.64 \pm 0.05 ; 9.34 \pm 1.03 / 10.32 \pm 0.86)$ at second trimester and $(9.81 \pm 0.16 / 10.83 \pm 0.76 ; 10.40 \pm 0.49 / 11.38$ \pm 0.08 ) at third trimester, Conversely, total and conjugated bilirubin followed a different trend of retrogressive decrease with increase in pregnancy time. Total and conjugated bilirubin $(\mathrm{mg} / \mathrm{dL})$ mean values for healthy pregnant women and pregnant women with typhoid infection at first trimester were $(0.56 \pm 0.87 / 0.69 \pm 0.09 ; 0.57 \pm 0.66 / 0.70$ $\pm 0.26)$, followed by second trimester $(0.43 \pm 1.06 / 0.56 \pm 0.05 ; 0.48 \pm 0.77 / 0.61 \pm 0.03)$ and third trimester $(0.32$ $\pm 0.57 / 0.45 \pm 0.11 ; 0.39 \pm 0.54 / 0.52 \pm 0.41$ ). Values of LFT results among pregnant women with typhoid infection were higher than that of healthy pregnant women $(\mathrm{p}<0.05)$. Therefore, pregnancy alterations and infections could cause significant alterations in the results of LFT among pregnant women.
\end{abstract}

Keywords: Typhoid infection; Liver function test (LFT); Physiological changes; Aspartate transaminase (AST); Alanine transaminase (ALT); Bilirubin

\section{Introduction}

Typhoid infection is among the most endemic diseases in the tropics. The disease has been associated with poverty and underdevelopment with significant morbidity and mortality [1]. Typhoid fever is an acute febrile infectious disease whose causative organism is the bacterium "Salmonella enterica serovar typhi." [2].The incubation period of typhoid and paratyphoid infections is 6-30 days. Salmonella represents a group of Gram-negative, facultative anaerobic pathogenic bacteria. Salmonella enteric serovar typhi ( $S$. typhi) is a facultative intracellular pathogen that causes typhoid fever in people. Salmonellae are individuals from the family of Enterobacteriaceae. The organism is non-capsulated, non-sporulating, flagellated, Gram-negative anaerobic bacilli and with external coat antigens. The bacterium is serologically positive for lipopolysaccharide antigens, protein flagellar antigen, and polysaccharide capsular antigen [3-4]. Typhoid bacteria interfere with the liver and its functions. The invasion of the liver cells by

\footnotetext{
${ }^{*}$ Corresponding author

E-mail address: christian_ike@rhemauniversity.edu.ng
} 
typhoid bacterium can cause organ congestion, sinusoidal blockage and cellular inflammation [5-6]. When these happen, the parenchyma transaminase and membranous alkaline phosphatase and gamma glutamyl transpeptidase enzymes of the liver leak out and find their way into the circulation, leading to increased enzyme activity [7]. The liver is enlarged and the bacteria cause inflammation of the liver. Untreated typhoid infection can lead to damage of the liver. Typhoid infection is widely recognized as a major public health problem in most developing tropical countries [8]. It is a systemic infectious disease characterized by an acute illness; the first typical symptoms are fever, headache, abdominal pain etc. Human being is the only reservoir and host for typhoid infection and is transmitted by fecal contaminated water and food in endemic areas especially by carriers handling food [9].

The liver is our body's most important organ after the heart, performing many important functions including metabolism, detoxification and formation of important compounds including blood clotting factors and albumin [10]. It is the largest organ in the human body, located in the right upper quadrant of the abdominal cavity, resting just below the diaphragm and lies to the right of the stomach. In a normal pregnancy, many physiological and hormonal changes occur within the human body, some of which can mimic those seen in women with liver disease. The pregnant woman experiences physiological changes to support fetal growth and development [11-12]. Pregnancy does not change size of liver but in the third trimester the enlarging uterus displaces the liver superiorly and posteriorly, which suggests significant hepatomegaly [13]. Routine liver function tests (LFT) usually include alanine and aspartate transaminases, total and conjugated bilirubin, alkaline phosphatase, and prothrombin time. Alanine (ALT) transaminase is predominantly found in liver, unlike aspartate (AST) transaminase. A typical hepatic activity comprises an ALT rise, accompanied by lesser elevation in AST [14-15]. Uterine muscle contractions during labor may increase AST or ALT activity levels [16]. In some studies, results showed slight increase in ALT during the second trimester of pregnancy compared to non-pregnant women, but all the values remained below the upper normal [1112]. An increase in ALT or AST levels during labor might be due to contractions of the uterine muscle [17-18].

Bilirubin is a waste product from the breakdown of red blood cells, which passes through the liver to become processed, where it is mixed with sugars to become water-soluble and is called direct or conjugated bilirubin. Before bilirubin passes through the liver for processing, it is water insoluble and is called indirect or unconjugated bilirubin. A damaged liver may be unable to process bilirubin, causing an increase in the total bilirubin levels. Bilirubin comes from haemoglobin ( $\mathrm{Hgb}$ ) as red blood cells (RBCs) breakdown either through physiological regeneration at the end of normal lifespan or as a consequence of pathologic hemolysis. Hgb releases heme which is converted inside macrophages to biliverdin which is then converted into unconjugated bilirubin (indirect bilirubin) which travels through the liver where it combines with glucuronic acid to form conjugated bilirubin (also known as bilirubin diglucuronide or direct bilirubin [19-21].The unconjugated bilirubin is water insoluble which impairs its ability to be excreted in bile, while conjugated bilirubin is water soluble. However, bilirubin is reported on an LFT as total and conjugated bilirubin [14]; [22-24]. Total bilirubin concentrations decreased during all three trimesters of pregnancy [12]; [25-26]; while conjugated bilirubin concentrations also decreased during the second and third trimesters [12]. Hyperbilirubinemia, total bilirubin levels greater than $1.3 \mathrm{mg} / \mathrm{dL}$, can cause jaundice and icterus. Continued hyperbilirubinemia can cause kernicterus or brain damage [16]; [27].Therefore, this study was targeted at evaluating the effect of typhoid infection on liver function assessment among pregnant women in Owerri, Imo State, Nigeria.

\section{Material and methods}

\subsection{Study area, sample size and distribution}

The study area was in Owerri, Imo State, while the study was conducted at Federal Medical Centre (FMC) Owerri, Imo state, Nigeria. The study was carried out between February, 2017 to November, 2017. A total of ninety (90) patients attending hospital were distributed as follows: thirty (30) healthy pregnant women, thirty (30) typhoid-infected pregnant women and another thirty (30) healthy non-pregnant women (serving as control) were studied. The study criteria included healthy pregnant women, pregnant women with typhoid infection and healthy non-pregnant women; all within the age range of 18 - 38 years and excluded pregnant women with gestational diabetes mellitus, hypertension (blood pressure equal to or greater than 140/90 $\mathrm{mm} \mathrm{Hg}$ ) and malaria. The study was among three groups of pregnancy time (first trimester, second trimester and third trimester), and each result was compared with control. All of these women were examined within a framework of preventive medicine for a routine clinical and biological checkup and none of the women included had evidence of liver disease. 


\subsection{Sample collection and processing}

Blood samples were taken from antecubital vein by plastic disposable syringes. The blood was transferred into a glass tubes. After an hour incubation at room temperature (clot retraction), centrifugation of the blood was done at a relative centrifugal force for 5 minutes.

\subsection{Microbiological analysis for Salmonella typhi identification}

About 10-15 ml of blood was collected with standard aseptic precautions from each patient and was inoculated into $40-45 \mathrm{ml}$ of brain heart infusion broth. Incubation was done at $37^{\circ} \mathrm{C}$. Sub culturing was performed on MacConkey agar plates which were incubated at $37^{\circ} \mathrm{C}$ for $18-24$ hours. Lactose non-fermenting colonies, if any, on subcultured plates were picked up and examined by microscopy after Gram-staining of the smears. Standard biochemical tests including motility test were performed for identification of Salmonella typhi.

\subsection{Liver function assessment and Widal test}

The centrifuged sera from 2.2 above were removed by disposable pasture pipettes and separated into sterile bottles and were stored in the refrigerator at $20^{\circ} \mathrm{C}$ until it's been used for the widal test and liver function assay within one week interval. Estimation of liver function assessment using kit method was done to include alanine transaminase (ALT), aspartate transaminase (AST), total and conjugated bilirubin during pregnancy period (first, second and third trimester) among healthy pregnant women, typhoid-infected pregnant women and comparing with a control group of healthy non-pregnant women.

\subsection{Statistical analysis}

Analysis of variance (ANOVA) was employed and used to analyze all data obtained from the three trimesters and compared with control group of healthy non-pregnant women. Results are expressed as mean \pm SD (standard deviation).

\section{Results}

The results of liver function tests (LFT) are shown in Figures 1-8. Serum alanine transaminase (ALT) for healthy pregnant women and pregnant women with typhoid infection are shown in Figures 1 and 2 . Serum alanine transaminase (iu/L) mean value for healthy pregnant women was $(8.93 \pm 1.07)$ in the first trimester, followed by $(10.62 \pm 1.19)$ in the second trimester, and with a slight reduction in the third trimester $(9.81 \pm 0.16)$, which was higher than that of the first trimester. This trend is applicable to all ALT result obtained for healthy pregnant women, pregnant women with typhoid infection and healthy non-pregnant women. Highest ALT values were observed in pregnant women with typhoid infection, with the highest value recorded in the second trimester (11.64 \pm 0.05$)$. ALT (iu/L) values obtained with healthy pregnant women (1st trimester $-8.93 \pm 1.07$, 2nd trimester $-10.62 \pm 1.19$, 3rd trimester $-9.81 \pm 0.16$ ), pregnant women with typhoid infection (1st trimester $-9.95 \pm 0.19$, 2nd trimester $-11.64 \pm 0.05$, 3rd trimester $-10.83 \pm 0.76)$ and healthy non-pregnant women (1st trimester $-8.36 \pm 0.88,2$ nd trimester $-8.50 \pm 0.76$, 3rd trimester - $8.15 \pm 1.34$ ) when compared are statistically significant $(\mathrm{p}<0.05)$.

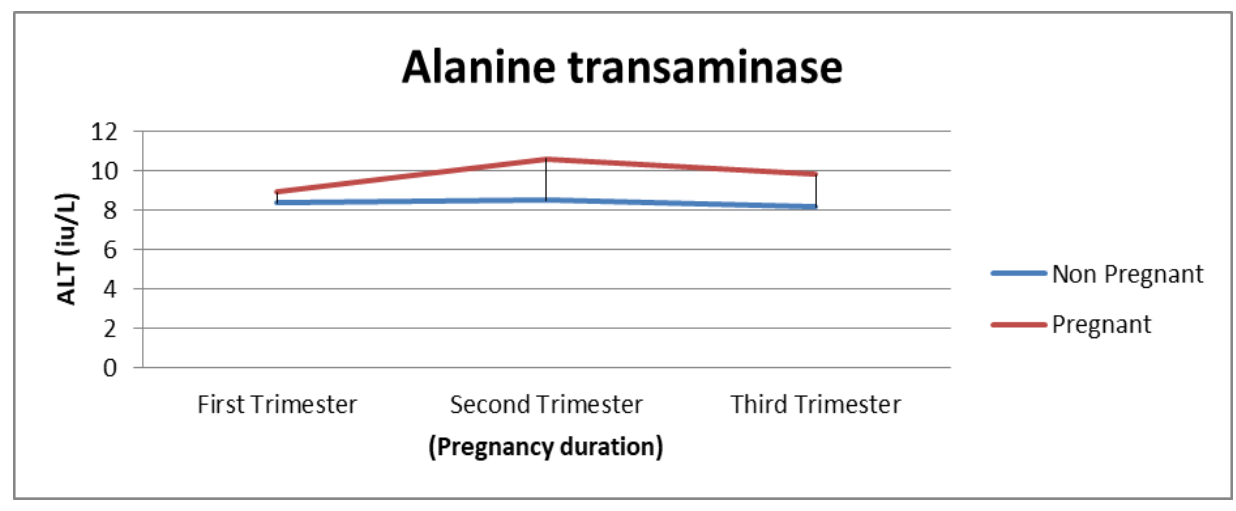

Figure 1 Serum alanine transaminase result for healthy pregnant women 


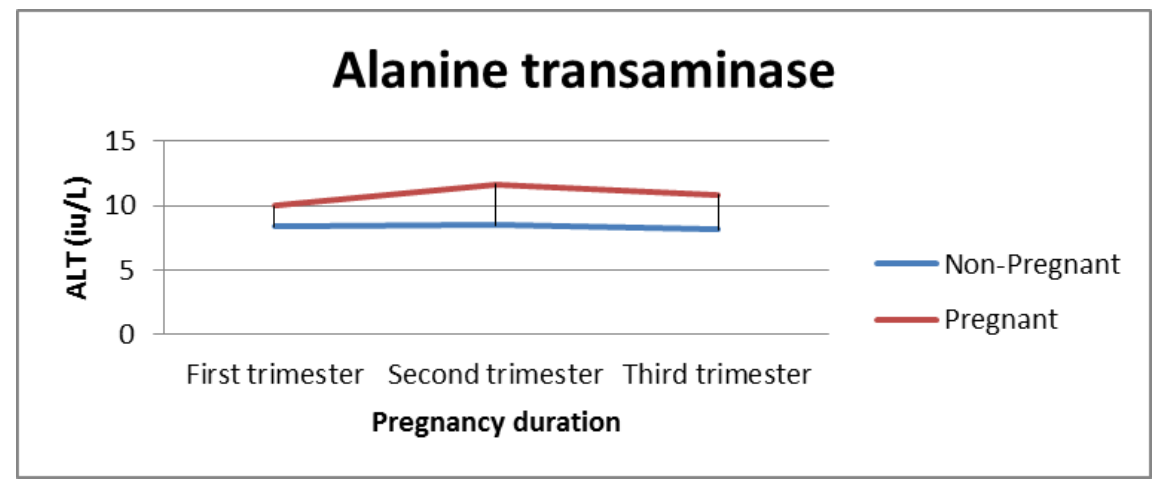

Figure 2 Serum alanine transaminase result for pregnant women with typhoid infection

Serum aspartate transaminase (AST) activity followed the trend of progressive value increase with increase in pregnancy time and is shown in Figures 3 and 4. Although, results obtained in the study showed insignificant increase in AST (iu/L) values among healthy non-pregnant women $(\mathrm{p}>0.05)$. There was no decline phase at any time during pregnancy period. Mean AST (iu/L) values for healthy pregnant women at first trimester was (7.52 \pm 0.45$)$, followed by second trimester value $(9.34 \pm 1.03)$ and third trimester $(10.40 \pm 0.49)$. Highest values of AST (iu/L) were obtained among pregnant women with typhoid infection; first trimester $(8.50 \pm 0.14)$, followed by second trimester $(10.32$ $\pm 0.86)$ and third trimester $(11.38 \pm 0.08)$. The results obtained in each of the trimesters for healthy pregnant women (1st trimester $-7.52 \pm 0.45$, 2nd trimester $-9.34 \pm 1.03$, 3rd trimester $-10.40 \pm 0.49$ ), pregnant women with typhoid infection (1st trimester $-8.50 \pm 0.14$, 2nd trimester $-10.32 \pm 0.86$, 3rd trimester $-11.38 \pm 0.08$ ) and healthy non-pregnant women (1st trimester $-7.74 \pm 0.99$, 2nd trimester $-7.80 \pm 1.81$, 3rd trimester $-8.11 \pm 0.65$ ) when compared are statistically significant $(\mathrm{p}<0.05)$.

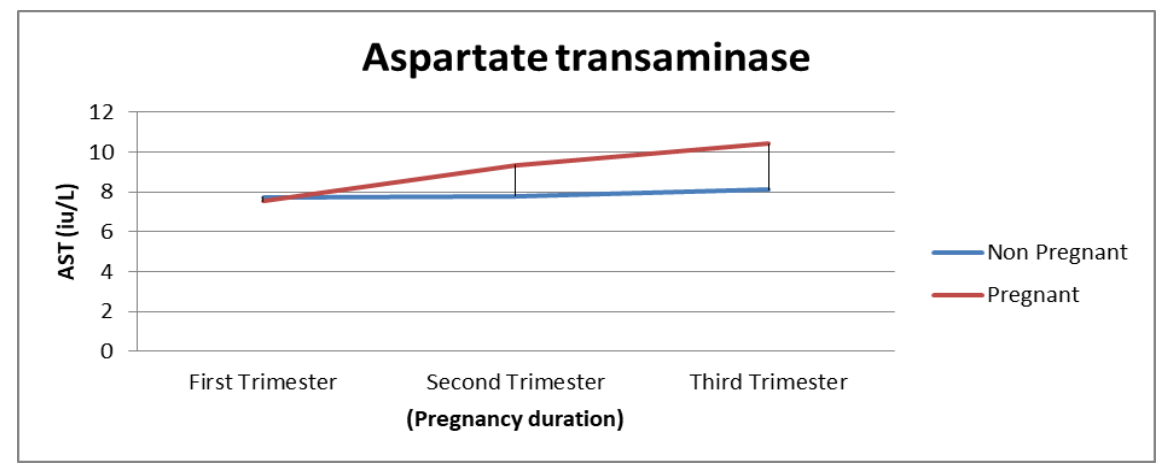

Figure 3 Serum aspartate transaminase result for healthy pregnant women

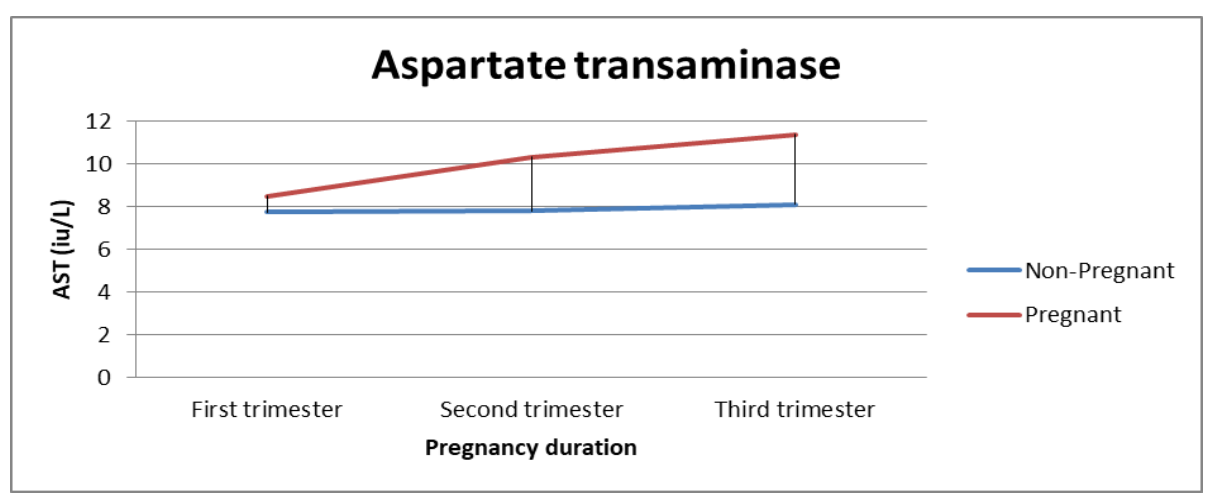

Figure 4 Serum aspartate transaminase result for pregnant women with typhoid infection

Conversely, total and conjugated bilirubin followed a different trend with that of AST and is shown in Figures 5, 6, 7 and 8 respectively. In Figures 5, 6, 7 and 8, values of both total and conjugated bilirubin obtained for healthy pregnant women and pregnant women with typhoid infection were retrogressively decreasing with increase in pregnancy time. 
However, results from healthy non-pregnant women did not follow a pattern rather were variable and insignificant for both total and conjugated bilirubin ( $\mathrm{p}>0.05)$. Mean total bilirubin $(\mathrm{mg} / \mathrm{dL})$ for healthy pregnant women at first trimester was $(0.56 \pm 0.87)$, followed by second trimester $(0.43 \pm 1.06)$, and third trimester $(0.32 \pm 0.57)$. Also, values of total bilirubin obtained from pregnant women with typhoid infection was higher than that of healthy pregnant women, with highest value in the first trimester $(0.69 \pm 0.09)$, followed by second trimester $(0.56 \pm 0.05)$ and lowest in the third trimester $(0.45 \pm 0.11)$. The values obtained in each of the trimesters for healthy pregnant women $(1 \mathrm{st}$ trimester - $0.56 \pm 0.87,2$ nd trimester $-0.43 \pm 1.06$, 3rd trimester $-0.32 \pm 0.57$ ), pregnant women with typhoid infection (1st trimester $-0.69 \pm 0.09$, 2nd trimester $-0.56 \pm 0.05$, 3rd trimester $-0.45 \pm 0.11$ ) and healthy non-pregnant women (1st trimester $-0.70 \pm 1.01$, 2nd trimester $-0.65 \pm 0.98$, 3rd trimester $-0.66 \pm 1.22$ ) when compared are statistically significant $(\mathrm{p}<0.05)$.

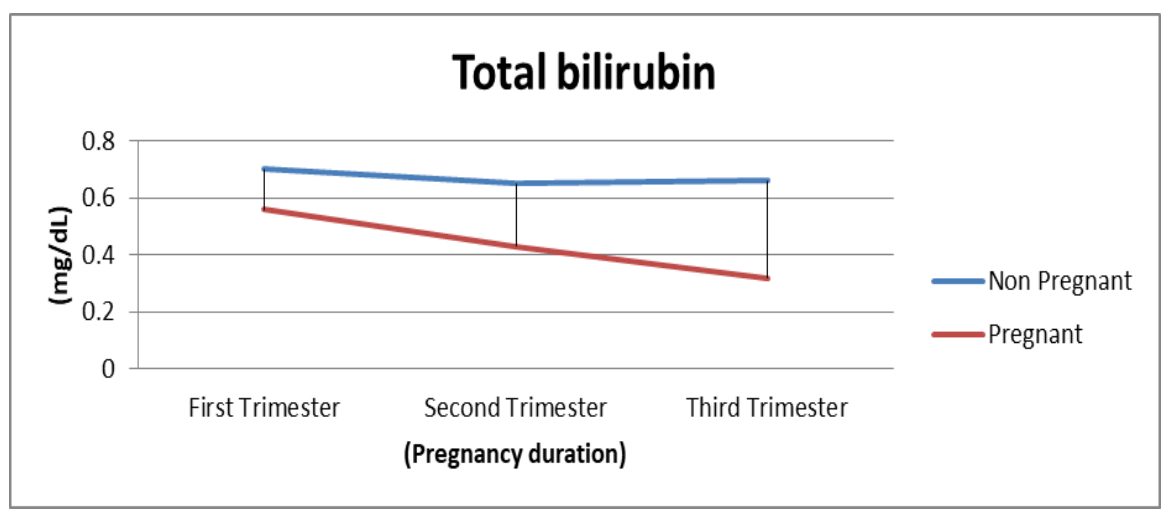

Figure 5 Total bilirubin result for healthy pregnant women

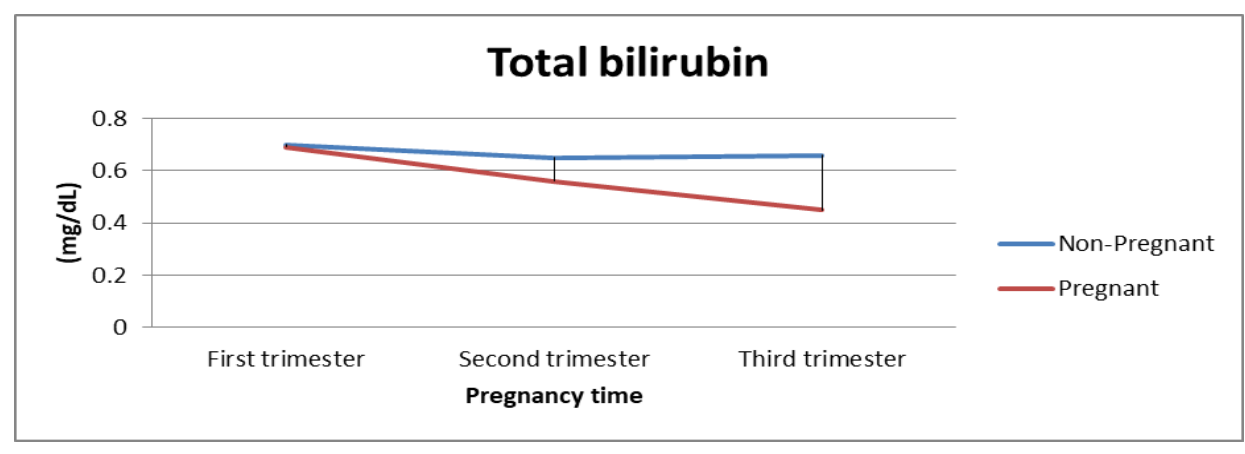

Figure 6 Total bilirubin result for pregnant women with typhoid infection

Conjugated bilirubin (mg/dL) for healthy pregnant women (Figure 7) recorded mean value at first trimester $(0.57$ $\pm 0.66)$, followed by second trimester $(0.48 \pm 0.77)$, and third trimester $(0.39 \pm 0.54)$. Values of conjugated bilirubin obtained from pregnant women with typhoid infection (Figure 8) were higher than that of healthy pregnant women (Figure 7), with highest value in the first trimester $(0.70 \pm 0.26)$, followed by second trimester $(0.61 \pm 0.03)$ and lowest in the third trimester $(0.52 \pm 0.41)$. Mean values obtained in each of the trimesters for healthy pregnant women (1st trimester $-0.57 \pm 0.66$, 2nd trimester $-0.48 \pm 0.77$, 3rd trimester $-0.39 \pm 0.54$ ), pregnant women with typhoid infection (1st trimester $-0.70 \pm 0.26$, 2nd trimester $-0.61 \pm 0.03$, 3rd trimester $-0.52 \pm 0.41$ ) and healthy non-pregnant women (1st trimester $-0.31 \pm 0.15$, 2nd trimester $-0.36 \pm 0.61$, 3rd trimester $-0.33 \pm 0.07$ ) when compared are statistically significant $(\mathrm{p}<0.05)$. 


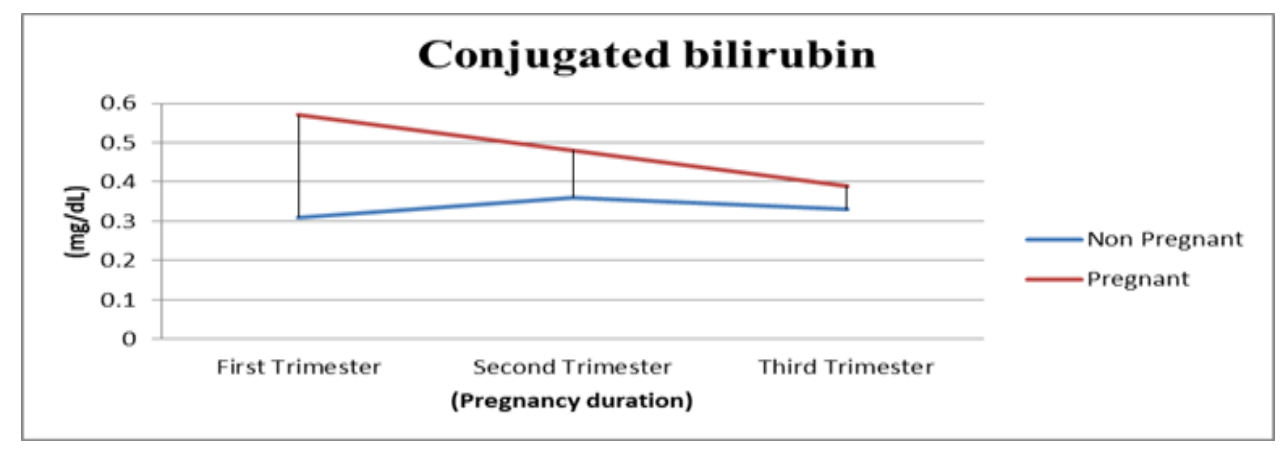

Figure 7 Conjugated bilirubin result for healthy pregnant women

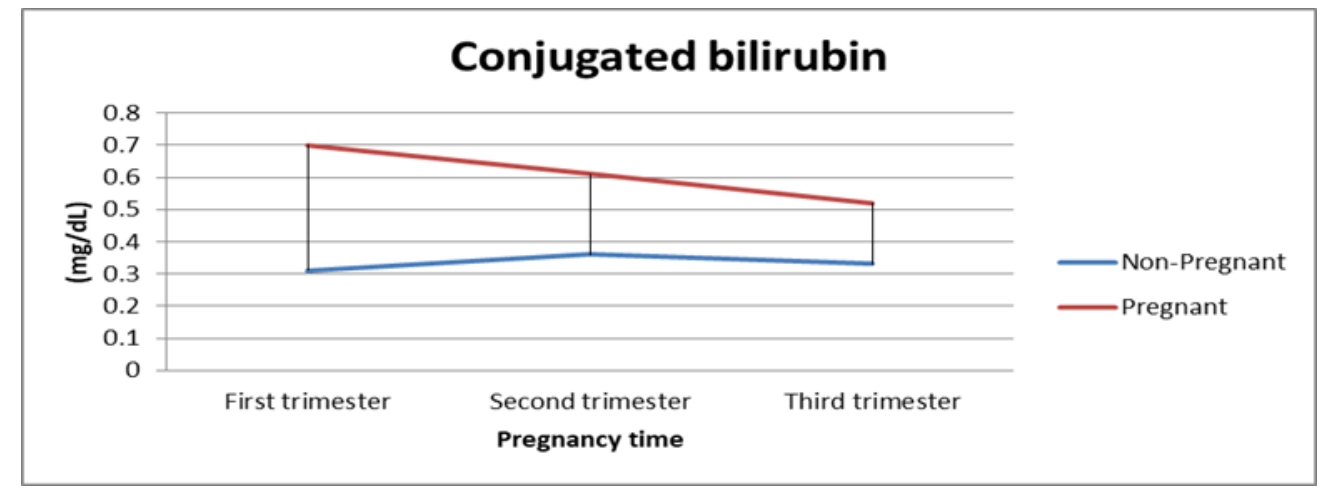

Figure 8 Conjugated bilirubin result for pregnant women with typhoid infection

\section{Discussion}

Liver disease is measured by determining various liver function tests to include alanine transaminase (ALT), aspartate transaminase (AST), total and conjugated bilirubin levels in the serum. Increased serum levels of the various enzymes in the liver function tests carried out on patients with typhoid fever only are indicative of a hepatocyte disorder. The liver function tests are used for evaluation of hepatic involvement during typhoid fever. According to [28], elevated serum enzymes (ALP, AST and ALT) in his work were discovered in 85\% of patients with typhoid fever. [29] and [30] in their findings reported that 62 and 70\%, respectively of patients with typhoid fever had elevated AST and ALT.

Serum alanine transaminase - ALT (iu/L) levels progressively increased from the first trimester to the second semester, before a sudden decrease in the third trimester. Although, ALT values in the third trimester was higher than that of the first trimester. Values of AST in healthy pregnant women, pregnant women with typhoid fever and healthy non-pregnant women when compared were statistically significant $(\mathrm{p}<0.05)$. This result was similar to the reports of [11-12]; [28-30], while two other studies by [31-32] found that serum ALT activity was significantly higher during the third trimester than in controls.

Aspartate transaminase - AST (iu/L) activity followed a trend of progressive value increase with increase in pregnancy time. It could be deduced that there is a correlation between pregnancy time and AST values, which would be said to be directly proportional. Although, same trend existed even with healthy non-pregnant women. But AST values were much higher during pregnancy periods with typhoid infection than during healthy pregnancy periods. Therefore, there is a clear correlation of AST values with pregnancy time on one end and typhoid infection on another end. The first trimester value was high, followed by second trimester and the highest was recorded in the third trimester. AST values among healthy pregnant women, pregnant women with typhoid infection and healthy nonpregnant women when compared were statistically significant $(\mathrm{p}<0.05)$. At the third trimester, mainly during labour, highest AST values were observed and could be linked with contraction of uterine muscles [17-18]. The result obtained in this study is in agreement with the assertions of [12]; [28-30] and [33]. Other studies found significant that supported the results obtained are the works of [26] and [34].

During the study, total and conjugated bilirubin activities decreased with pregnancy time. Total bilirubin levels had consistent decreases that are lower in expectant mothers than in healthy non-pregnant women in all three trimesters. 
However, it was different for conjugated bilirubin as though there was consistent trend of retrogressive value decrease along pregnancy duration line but values obtained were high in expectant mothers than in non-pregnant women. The least value for total bilirubin and conjugated bilirubin for healthy pregnant women were recorded during the third trimester. Values of total and conjugated bilirubin obtained in this study for pregnant women with typhoid infection were higher than that of healthy pregnant women. The values obtained for total bilirubin and conjugated bilirubin among healthy pregnant women, pregnant women with typhoid infection and healthy non-pregnant women when compared were statistically significant $(\mathrm{p}<0.05)$. This result is in agreement with the reports of [12]; [28-30]; [33] and [35]. Meanwhile, hemodilution with pregnancy age had explained in part the cause for corresponding decrease in bilirubin concentration [36-40].

\section{Conclusion}

Typhoid still remain a major public health problem in many developing countries of the world and if untreated can lead to increase in the serum levels of alanine transaminase, aspartate transaminase, total bilirubin and conjugated bilirubin.

Liver function test (LFT) results among pregnant women in most cases are altered by the normal changes that occur during pregnancy and also when infections like typhoid occur. Serum ALT and AST increase significantly but progressively with pregnancy time and at occurrence of typhoid infection, while total and conjugated bilirubin decreases significantly with pregnancy time and at occurrence of typhoid infection. These pregnancy and infectionrelated alterations are usually considered when evaluating LFT values in pregnant woman, otherwise results can be misinterpreted.

\section{Compliance with ethical standards}

\section{Acknowledgments}

The authors are grateful to the management and staff of Federal Medical Centre (FMC), Owerri for the support provided to carry out the research.

\section{Disclosure of conflict of interest}

No conflict of interest.

\section{Statement of ethical approval}

The study was approved by the Ethical Committee of Federal Medical Centre (FMC), Owerri, Imo State, Nigeria.

\section{Statement of informed consent}

Informed consent was obtained from all individual participants included in the study.

\section{References}

[1] White NJ. (2011). A vaccine for malaria. New England Journal of Medicine, 12, 365-367.

[2] Parry CM, Hien TT, Dougan G, White NJ and Farrar JJ. (2002). Typhoid fever. New England Journal of Medicine, 347, 1770-1782.

[3] Baker S, Holt KE, Clements AC, Karkey A, Arjyal A, Boni MF, Dongol S, Hammond N, Koirala S, Duy PT, Nga TV, Campbell JI, Dolecek C, Basnyat B, Dougan G and Farrar JJ. (2011). Combined high-resolution genotyping and geospatial analysis reveals modes of endemic urban typhoid fever transmission. Open Biology, 1(2), 1-13.

[4] Raffatellu M, Wilson RP, Winter SE and Bäumler AJ. (2008). Clinical pathogenesis of typhoid fever. Journal of Infections in Developing Countries, 2(4), 260-266.

[5] Jarike AE, Emuveyon EE and Idogun SF. (2002). Pitfalls in the interpretation of liver parenchymal and membranous enzyme results. Pre-clinical $P$. falciparum malaria in the Nigerian environment. Nigerian Journal of Clinical Medicine, 10, 21-27. 
[6] Petit PL and Wamola IA. (1994). Typhoid fever: A review of its impact and diagnostic problems. East African Medicine Journal, 71, 183-188.

[7] Burtis CE, Ashwood A and Border B. (2001). Liver Function: Tietz Fundamentals of Clinical Chemistry. 5 Edition, Saunders Company, Philadelphia, 748-770.

[8] Kayode OT, Kayode AAA and Awonuga 00. (2011). Status of selected hematological and biochemical parameters in malaria and malaria-typhoid co-infections. Journal of Biological Sciences, 11, 367-373.

[9] Uneke CJ. (2008). Concurrent malaria and typhoid fever in the tropics: The diagnostic challenges and public health implications. Journal of Vector Borne Diseases, 45, 133-142.

[10] Hunt CM and Sharara ALA. (1999). Liver disease in pregnancy. American Academy of Family Physician, 59(4), 465-475.

[11] Loganathan G, George R, Eapen CE, Mathai M, Jasper P, Seshadri L, Viswanathan S, Paul S, Joseph G, Balasubramanian KA and Chandy GM. (2005). Liver function tests in normal pregnancy: A study from southern India. Indian Journal of Gastroenterology, 24(6), 268-269.

[12] Bacq Y, Zarka O, Brechot JF, Mariotte N, Tichet SVJ and Weill J. (1996). Liver function test in normal pregnancy: A prospective study of 103 pregnant women and 103 matched control. Hepatology, 23 (5), 1030-1034.

[13] Alonso AG. (2006). Effect of pregnancy on preexisting liver disease physiological changes during pregnancy. Annals of Hepatology, 5(3), 184-186.

[14] Al-Jameil N, Hajera HT, Al-Mayouf HH, Al-Shenefy AA and Khan FA. (2015). Liver function tests as probable markers of preeclampsia-A Prospective study conducted in Riyadh. Journal of Clinical Analytical Medicine, 6, 461-464.

[15] Kaur S, Khan S and Nigam A. (2014).Hematological profile and pregnancy: a review. International Journal of Advances in Medicine, 1, 68-70.

[16] Westbrook RH, Dusheiko G and Williamson C. (2016). Pregnancy and liver disease. Journal of Hepatology, 64, 933-945.

[17] Meade BW and Rosalki SB. (1993). Serum enzyme activity in normal pregnancy and the newborn. Journal of Obstetrics Gynecology, 70, 693-700.

[18] Reichard H, Wiqvist N and Yllner S. (1960). Chloroform anesthesia in obstetrics: its effect of the serum activity of ornitine carbamyl transaminase, glutamic oxaloacetic transaminase, and glutamic pyruvic transaminase. Acta Obstetrics Gynecology Scand, 39, 661-674.

[19] Arika WM, Nyamai DW, Osano KO, Ngugi MP and Njagi ENM. (2016). Biochemical markers of in-vivo hepatotoxicity. Journal of Clinical Toxicology, 6, 297-311.

[20] Nwosu DC, Nwanjo HU, Obeagu EI, Ibebuike JE and Ezeama MC. (2015). Changes in liver enzymes and lipid profile of pregnant women with malaria in Owerri, Nigeria. International Journal of Current Research \& Academic Review, 3, 376-383.

[21] Odhiambo C, Oyaro B, Odipo R, Otieno F and Alemnji G. (2015). Evaluation of locally established reference intervals for hematology and biochemistry parameters in western kenya. Plos one 10: e0123140.

[22] Akinlaja 0. (2016). Hematological changes in pregnancy-The preparation for intrapartum blood loss. Obstetrics Gynecol International Journal, 4,100- 109.

[23] Tran TT, Ahn Jand Reau NS. (2016). ACG Clinical Guideline: Liver Disease and Pregnancy. American Journal of Gastroenterology, 8, 1-14.

[24] Venugopal S and Rajamma CK. (2015). Liver function tests in first and third trimesters of normal pregnancy in a population of North Kerala. Journal of International Medicine Dentistry, 2, 215-221.

[25] Jarnfeit-Samsioe A, Eriksson B, Waldenstrome J and Samsioe G. (1986). Serum bile acids, gamma glutamyl transferase and routine liver tests in emetic and non-emetic pregnancies. Gyencology Obstetetrics Invest, 21, 169-176.

[26] Knopp RH, Bergelin RO, Wahl PW, Walden CE and Chapman MB. (1985). Clinical chemistry alteration in pregnancy and oral contraceptive use. Obstetric Gynecology, 66, 682-690. 
[27] Abduljalil K, Furness P, Johnson TN, Rostami-Hodjegan A and Soltani H. (2012). Anatomical physiological and metabolic changes with gestational age during normal pregnancy. Clinical Pharmacokinet, 51, 365-396.

[28] Ali HA, Ahmed MA, Abbdullam U, Zulfa OD and Hina HS. (2007). Hepatic dysfunction in typhoid fever. Pathological Journal of Medical Science, 12, 81-84.

[29] Morgenstern R and Hayes PC. (1991). The liver in typhoid fever: Always affected, not just a complication. American Journal of Gastroenterology, 86, 1235-1239.

[30] Mirsadraee M, Shirdel A and Roknee F. (2007). Typhoid myopathy or typhoid hepatitis: A matter of debate. Indonesian Journal of Medical Microbiology, 25, 351-353.

[31] Cerutti R, Ferraris S, Grella P, Castelli, Women SGP and Rizzotti P. (1976). Bahaviour ofserum enzymes in pregnancy.Clinical Exp Obstetrics Gynecology, 322-24.

[32] Salgo L and Pal A. (1989). Variation in some enzymes in amniotic fluid and maternal serum during pregnancy. Enzyme, 41, 101-107.

[33] Moore M and Nelson-Piercy C. (2011). Pregnancy and the liver. British Journal of Hospital Medicine, 72, 170173.

[34] Elliott JR and O'kell RT. (1971). Normal clinical values for pregnant women at term. Clinical Chemistry, 17, 156157.

[35] Mutua DN, Njagi MNE and Orinda G. (2018) Liver Function Tests in Normal Pregnant Women. Journal of Liver, 7 (2), 22-28.

[36] Al-Salahy M, Shnawa B, Abed G, Mandour A and Al-Ezzi A. (2016). Parasitaemia and Its Relation to Hematological Parameters and Liver Function among Patients Malaria in Abs, Hajjah, Northwest Yemen. Interdisciplinary Perspectives on Infectious Diseases.

[37] Dunia MR. (2015). Effect normal pregnancy and duration on liver enzymes tests. Global.Journal Medical Research, 15, 2-5.

[38] Miri-Dashe T, Osawe S, Tokdung M, Daniel N and Choji RP. (2014). Comprehensive reference ranges for hematology and clinical chemistry laboratory parameters derived from normal nigerian adults. Plos one 9: e93919.

[39] Gohel MG, Joshi AG, Anand JS, Makadia JS and Kamariya CP. (2013). Evaluation of changes in liver function test in first, second and third trimester of normal pregnancy. International Journal Reproductive Contraceptive Obstetrics Gynecology, 2, 616-620.

[40] Walker I, Chappell LC and Williamson C. (2013). Abnormal liver function tests in pregnancy. British Medical Journal, 347, f6055.

\section{How to cite this article}

Ike CC, Akwari DK, Ogwuegbu HO and Chikezie JA. (2019). Typhoid infection and its effect on liver function assessment among pregnant women in Owerri, Imo State, Nigeria. GSC Biological and Pharmaceutical Sciences, 8(1), 105-113. 